\title{
ELEMENTOS NEOPLATÓNICOS EN EL SIRR AL-ASRĀR (SECRETUM SECRETORUM) ATRIBUIDO A ARISTÓTELES
}

\author{
RAFAEL RAMÓN GUERRERO \\ UNIVERSIDAD COMPLUTENSE. MADRID
}

\begin{abstract}
Resumen
Herederos de la tradición helenística de las escuelas de Alejandría y Atenas, los árabes partieron de un Aristóteles neoplatonizado, sistematizado en diversas obras que le fueron atribuidas. Entre ellas destaca el muy difundido Sirr al-asrār o Secretum secretorum, según el título de la versión latina, en la que algunas de las doctrinas genuinas de Aristóteles se encuentran mezcladas con elementos platónicos, neoplatónicos, neopitagóricos y herméticos. Presentada como una carta de Aristóteles a Alejandro, ofrece en uno de sus capítulos una explicación del universo de carácter neoplatónico: afirma la realidad de Dios como sustancia simple espiritual de la que emana jerárquicamente el resto de la creación, siendo el hombre el elemento unificador de todas las esencias creadas.
\end{abstract}

\section{Palabras clave}

Pseudo-Aristóteles, Secreto de los secretos, neoplatonismo, emanación, universo, hombre.

\section{Abstract}

Inheritors of the Alexandrian and Athenian Hellenistic tradition, the Arabs drew from a Neoplatonized Aristotle systematized through different attributed works, among them, the Sirr al-asrär, the Secretum secretorum in the Latin translation in which some genuine Aristotle doctrines are blended with Platonic, Neoplatonic, Neopythagorean and Hermetic elements. Brought in as a letter from Aristotle to Alexander, one of its chapters provides a Neoplatonic explanation of the Universe: while claiming that God's nature is a simple spiritual substance from which the rest of the creation arisen, man is viewed as the unifying element of all created essences. 
Pseudo-Aristotle, Secret of secrets, Neo-Platonism, Emanation, Universe, Man.

La aportación de la filosofía neoplatónica en la formulación y desarrollo de gran parte de las doctrinas filosóficas árabes ha sido suficientemente destacada a lo largo de la historia. La filosofía que se constituyó en el mundo islámico tuvo su punto de partida en el neoplatonismo, recibido con doctrinas aristotélicas, cuya razón está en que el Islam se había instalado en un ámbito cultural donde el neoplatonismo era la filosofía reinante, la cual, además, ofrecía afinidades con el pensamiento islámico. Doctrinas religiosas como las de la Unidad divina y la creación del mundo encontraron explicación filosófica en la consideración neoplatónica del Uno y en la doctrina de la emanación de la multiplicidad a partir del Uno originario, que permitía salvar la unicidad e inmutabilidad divinas y establecer un abismo ontológico entre Dios y sus criaturas. El neoplatonismo que los árabes recibieron venía impregnado del sentido de la unidad filosófica representada por las doctrinas de Platón y Aristóteles, coincidentes en sus puntos más esenciales: la escuela de Atenas había impulsado la enseñanza de Aristóteles creyendo que el estudio de éste preparaba la comprensión de los diálogos platónicos y la escuela de Alejandría siguió la misma directriz. Fue una idea que mantuvieron los mismos filósofos en el mundo islámico. Así lo expresó al-Fārābī:

'Cuando he visto a la mayoría de las gentes de mi tiempo excitarse y disputar vivamente en torno a la temporalidad del mundo o a su eternidad y pretender que entre los dos más renombrados filósofos de la antigüedad existe divergencia en cuanto a la demostración del Creador primero y a la existencia de las causas segundas, en las doctrinas del alma y del entendimiento, en lo que toca al premio o castigo de las buenas y malas acciones y en otros problemas de ética, política y lógica, me propuse en este tratado armonizar las opiniones de ambos filósofos y explicar lo que conduce a ello, yuxtaponiendo sus doctrinas a fin de que aparezca su mutua correspondencia, cese toda perplejidad e indecisión en quienes leen sus libros y quede fijamente determinado el origen de tales dudas. La explicación de todo esto es de lo más importante que se puede proponer y su comentario y clara exposición lo más útil que se puede desear. La filosofía es la ciencia de los seres en cuanto tales: Platón y Aristóteles son sus fundadores y los que han desarrollado sus primeros principios y alcanzado sus últimas consecuencias. A ellos hay que acudir 
en toda cuestión filosófica, grande o pequeña, fácil o difícil. Sus opiniones en esta materia constituyen un principio indiscutible, por exentas de oscuridad y confusión'. ${ }^{1}$

La búsqueda de una doctrina que armonizara los pensamientos de los dos grandes maestros griegos fue uno de los motivos por los que se neoplatonizó el pensamiento de Aristóteles y por los que aparecieron obras atribuidas a éste, cuyo contenido podía servir para explicar las principales cuestiones que interesaban a los musulmanes, presentando a Aristóteles como autor de una doctrina que coincidía con la religión. Ello tuvo como consecuencia que la filosofía fuera completamente aceptada en el mundo religioso islámico. Por esta razón, cobraron gran importancia escritos pseudo-aristotélicos, en los que algunas doctrinas genuinas del filósofo de Estagira están claramente mezcladas con elementos platónicos, neoplatónicos, neopitagóricos y herméticos.

Los biógrafos citan algunos de estos apócrifos. Ibn Ŷulŷul, que escribió en alAndalus a fines del siglo X, cita cuatro de los más importantes: la Teología, ${ }^{2}$ los Testamentos, el Secreto de los secretos y el Libro de la manzana, ${ }^{3}$ que prueban que estas obras pseudo-aristotélicas habían adquirido gran difusión, al menos en su referencia externa. ${ }^{4} \mathrm{~A}$ éstas hay que añadir el llamado en el mundo latino Liber de causis, conocido en el mundo árabe con el título Kitāb al-jayr al-maḥ (Libro del Bien puro), que ha tenido su propia historia en lo que se refiere a su posible autor. Sin embargo, ya en el siglo $\mathrm{X}$, el autor oriental Ibn al-Nadìm cita en su Fihrist (Catálogo) un Kitāb al-jayr al-awwal (Libro del Bien Primero) entre las obras de

1 Fārābī: Kitāb al-ŷam b bayn ra'y al-ḥakīmayn Aflātūn al-ilāhī wa-Arisțutālīs (Armonía entre los sabios Platón el divino y Aristóteles), ed. en Al-Fārābì's philosophischen Abhandlungen aus Londoner, Leidener und Berliner Handschriften, ed. F. Dieterici, Leiden: J. Brill, 1890, p. 1. Trad. española: Manuel Alonso: 'Al-Fārābī. Concordia entre el divino Platón y el sabio Aristóteles', Pensamiento, 25 (1969) pp. 21-70. Trad. francesa: Deux traités philosophiques. L'harmonie entre les opinions des deux sages, le divin Platon et Aristote. De la religion, Introduction, traduction et notes par D. Mallet, Damasco, 1989. L'armonia delle opinioni dei due sapienti, il divino Platone e Aristotele. Introduzione, testo arabo, traduzione e commento di C. Martini Bonadeo. Prefazione di G. Endress, Pisa: Edizioni Plus Pisa University Press, 2008.

2 El texto árabe de la Teología fue editado por Friedrich Dieterici: Die sogennante Theologie des Aristoteles, Leipzig, 1882, y, más recientemente, por Abdurrahmān Badawi: Plotinus apud arabes Theologia Aristotelis et fragmenta quae supersunt, collegit, edidit et prolegomenis instruxit A. Badawi, El Cairo: al-Nahda, 1955. Hay traducción española: Pseudo-Aristóteles: Teología, traducción, introducción y notas: Luciano Rubio, Madrid: Ediciones Paulinas, 1978.

3 Cf. traducción castellana de la Vida de Aristóteles de este autor en José A. García-Junceda y Rafael Ramón-Guerrero: 'La vida de Aristóteles de Ibn Ŷulŷul', Anuario del Departamento de Historia de la Filosofía y de la Ciencia, U.A.M., curso 1984-85, pp. 109-123.

4 Una descripción de estas obras puede encontrarse en Francis E. Peters: Aristoteles Arabus. The Oriental translations and commentaries on the Aristotelian Corpus, Leiden: Brill, 1968. 
Proclo, ${ }^{5}$ que fácilmente puede identificarse con el Liber de Causis, porque éste no es sino un compendio de los Elementos de Teología de Proclo, como ya fue puesto de manifiesto por Santo Tomás de Aquino por vez primera, cuando conoció la traducción latina del texto griego realizada por Guillermo de Moerbeke en 1268, al decir lo siguiente:

'Se encuentran diversos escritos sobre los primeros principios; estos escritos están divididos en diversas proposiciones. En griego se encuentra uno: es el libro que contiene 211 proposiciones del platónico Proclo y que se titula Elementatio theologica. Por otra parte, en árabe existe este libro, que entre los latinos se llama Liber de causis; consta que ha sido traducido del árabe y que no existe griego. Parece que ha sido extraído por algún filósofo árabe del susodicho libro de Proclo, porque todo lo que en éste está contenido está también, de manera detallada, en aquél'.

Además de contener un resumen de los Elementos de teología de Proclo, hay también una presencia de otras fuentes evidentes, como la propia Teología y, quizá también, el pseudo-Dionisio.?

Pero no es el momento de tratar de estos textos. Quiero ocuparme ahora de otra de las obras atribuidas a Aristóteles, una de las más difundidas en el mundo árabe y en Europa medieval, la que lleva por título Kitāb Sirr al-asrār y en latín Secretum Secretorum. Parece que esta obra fue uno de los primeros textos atribuidos a Aristóteles en el mundo árabe y se inscribe dentro de la tradición del género literario conocido por el nombre de 'Espejos de príncipes', que consisten en un conjunto de apólogos y proverbios con ejemplos político-morales, ${ }^{8}$ que utilizan la metáfora del espejo.

El texto original árabe se presenta como una carta de Aristóteles a Alejandro en la que le ofrece consejos políticos e información sobre ciencias diversas, incluidas las ocultas. Es en realidad un texto compuesto a partir de obras

Ibn al-Nadīm: Kitāb al-Fihrist, ed. G. Flügel, Leipzig: Verlag von F. C. W. Vogel, 1872, p. 252.

6 In librum De causis expositio, ed. C. Pera, Turin-Roma, Marietti, 1955, Lectio I, Proemium 9, pp. 4-5. Ed. H. Saffrey, Fribourg-Louvain : Société Philosophique - Éditions E. Nauwelaerts, 1954, p. 3.

7 No es cronológicamente impensable. El corpus areopagítico era conocido en Siria en el siglo VI y parece que la versión siriaca remonta a Sergio de Reshaina (m. 536). Cf. Cristina D’Ancona: Recherches sur le Liber de Causis, París : Vrin, 1995.

8 Ha estudiado las condiciones histórico-sociales en que surgieron estos 'Espejos' medievales José A. Maravall: 'La concepción del saber en una sociedad tradicional', en Estudios de Historia del pensamiento español. Serie Primera. Edad Media, Tercera edición ampliada, Madrid: Ediciones Cultura Hispánica, 1983, pp. 201-254. Algunas de las tesis expuestas por Maravall necesitan ser revisadas, como, por ejemplo, la que sostiene que la tarea intelectual de los árabes se limitó a copiar y coleccionar textos de la antigüedad. 
anteriores, reconocidas e identificadas por M. Grignaschi. ${ }^{9}$ Una de ellas sería la Risāla fì l-siyāsa al- 'āmmiyya (Epistola sobre el gobierno del pueblo), que es una de las Epístolas de Aristóteles a Alejandro, ${ }^{10}$ conjunto de cartas que remontan a una novela epistolar clásica, aunque aquella Risāla contiene añadidos de época árabe, por lo que podría ser el más antiguo 'Espejo de príncipes' del mundo islámico conocido, compuesto quizá en la primera mitad del siglo VIII. ${ }^{11}$

Esta Epístola fue el modelo sobre el que se formó un Kitāb al-siyāsa (Libro de la política), exposición sistemática de las enseñanzas de la Epístola, con adiciones tomadas de la tradición política sasánida; este Kitāb apenas debió tener difusión, puesto que sólo se ha conservado en una paráfrasis turca hecha por un sabio del siglo XVI, Manū Nawālī, quien añadió un florilegio de leyendas sobre Aristóteles y Alejandro.

De este Kitāb al-siyāsa derivó, a su vez, el Sirr al-asrār, ${ }^{12}$ publicado por A. Badawi, ${ }^{13}$ al que se le han añadido un conjunto de ciencias ocultas y curiosidades que apenas tienen interés. Pretende ser una traducción del griego al siríaco y del siríaco al árabe, hecha por Yuhannā ibn al-Bițrīq, tal como se lee en la introducción y tal como recoge la biografía de este traductor dada por el historiador andalusí Ibn Ŷulŷul en su Ṭabaqāt al-ațibbā, ${ }^{14}$ obra escrita en el año 987, lo que permite suponer que una primera redacción del Sirr ya era conocida antes de esa fecha en al-Andalus; además, el mismo historiador lo cita entre las obras de Aristóteles, compuesta de ocho capítulos. Según Grignaschi, el texto conocido por Ibn Ŷulŷul sería el arquetipo inicial sobre el que luego se formaron las dos redacciones hoy conocidas del texto, la corta, compuesta de estos ocho capítulos, que dataría del siglo XI o primera mitad del siglo XII y la más próxima al arquetipo, ${ }^{15} \mathrm{y}$ la larga, dividida en diez tratados y conservada en la mayoría de los manuscritos árabes. ${ }^{16}$

9 Pueden verse sus artículos: 'L'origine et les métamorphoses du Sirr al-asrâr', Archives d'Histoire Doctrinale et Littéraire du Moyen Age, 43 (1976), pp. 7-112. 'Remarques sur la formation et l'interprétation du Sirr al-Asrār', en Pseudo-Aristoteles The Secret of Secrets. Sources and Influences, edited by W. F. Ryan and Charles B. Schmitt, London: The Warburg Institute, 1982, pp. 3-33.

10 Mario Grignaschi: 'Les «Rasā'il Arisțātālīs ilà-l-Iskandar» de Sālim Abū-l-'Alā’ et l'activité culturelle à l'époque Omayyade', Bulletin d'Études Orientales, 19 (1965-1966), pp. 7-83.

11 Mario Grignaschi: 'Le Roman épistolaire classique conservé dans la version arabe de Sālim Abūl-Alā”, Le Museon, 80 (1967), pp. 211-264.

12 Cf. Mahmoud Manzalaoui: 'The Pseudo-Aristotelian Kitāb sirr al-asrār', Oriens, 23-24 (1970-71), pp.147-257.

13 Al-uṣūl al-yūnāniyya li-l-nazariyyāt al-siyāsiyya fï l-Islām [Fontes Graecae doctrinarum politicarum islamicarum], El Cairo, ex typis Bibliothecae Aegyptiacae, 1954, pp. 65-171.

14 op. cit., p. 67.

15 Mario Grignaschi: 'Remarques sur la formation...', pp. 6-7.

16 Es la que corresponde al texto árabe editado por Badawi. 
El Sirr tuvo una amplia difusión en el mundo occidental. ${ }^{17}$ Fue traducido al latín por dos veces, una en el siglo XII, en versión fragmentaria de Juan Hispalense, con el título Poridat de poridades, para una reina hispana, quizá la hija de Alfonso VI, Teresa de León (m. 1130), madre de Alfonso Enríquez, el primer rey de Portugal (1109-1185), de la que se conservan unas ciento cincuenta copias manuscritas, ${ }^{18}$ y otra en el siglo XIII, por Felipe de Trípoli, ${ }^{19}$ de la que existen más de trescientos manuscritos. Fue traducido también al hebreo en la península Ibérica, a comienzos del siglo XIII, por un judío oriundo de Granada. ${ }^{20}$ Luego al inglés, al francés, al italiano, al alemán, al ruso, al checo e, incluso, al aragonés, ${ }^{21}$ entre otras lenguas. Todas ellas dan testimonio del interés que, a pesar de todo, tuvo para muchos lectores, movidos en primer lugar, por la popularidad de la leyenda de Alejandro, puesto que los latinos estaban al tanto de la correspondencia entre Aristóteles y Alejandro, como se deduce de una cita de la Disciplina clericalis de Pedro Alfonso en la que se copia un párrafo de una carta de Alejandro a su discípulo, que parece remitir al Sirr al-asrār, ${ }^{22}$ y, en segundo lugar, por los aspectos éticos y políticos que en él se ofrecen.

Aunque el texto fue comentado por Roger Bacon, ${ }^{23}$ sin embargo los autores latinos de los siglos XIII y XIV apenas mencionan esta obra, quizá porque fue sospechosa de nigromancia para las autoridades eclesiásticas, hasta el punto de que el mismo Bacon se quejó de la stulticia aliquorum, por las mutilaciones que hicieron al texto. ${ }^{24}$ Un florilegio medieval, el Parvi flores, compuesto entre los años 1267-1325 y cuyo autor pudo ser Marsilio de Padua, extrae un cierto número de

17 Cf. Mario Grignaschi: 'La difussion du «Secretum secretorum» (Sirr al-Asrār) dans l'Europe Occidental', Archives d'Histoire Doctrinale et Littéraire du Moyen Age, 47 (1980), pp. 7-70.

18 Secreto de los secretos. Poridat de las poridades. Versiones castellanas del Pseudo-Aristóteles Secretum secretorum, estudio y edición de Hugo O. Bizarri, Valencia: Publicacions de la Universitat de València, 2010.

19 Cf. Mahmoud Manzalaoui: 'Philip of Tripoli and his Textual Methods', en Pseudo-Aristoteles The Secret of Secrets, pp. 55-72.

20 Moshe Gaster, 'The Hebrew Version of the Secretum secretorum', Journal of the Royal Asiatic Society, (1907), pp. 879-912; (1908) pp. 1065-1084. Cf. Amitai L. Spitzer: 'The Hebrew Translation of the Sod ha-Sodot and its place in the transmission of the Sirr al-asrār', en Pseudo-Aristoteles The Secret of Secrets, pp. 34-54.

${ }^{21}$ Juan Fernández de Heredia, Grand Master of the Knights of St. John of Jerusalem: The Aragonese Version of the Secreto Secretorum, (From the Unique Escorial MS. Z.I.2). Edited by Lloyd Kasten, Madison: The Hispanic Seminary of Medieval Studies, 1999.

22 Cf. Disciplina clericalis, introducción y notas de María Jesús Lacarra, traducción de Esperanza Ducay, versión española con texto latino, Zaragoza, Guara Editorial, 1980, p. 54; texto latino en p. 116; nota 10 en pp. 101-102.

23 Cf. Robert Steele, Opera hactenus inedita Rogeri Baconi. Fasc. V: Secretum secretorum, Oxford, 1920.

24 Cf. Mario Grignaschi, 'La diffusion...', pp. 13 y ss. 
sentencias del De regimine principum Aristotelis eruditio, identificado por la editora de este texto con el Secretum secretorum. ${ }^{25}$

El contenido de la obra es muy diverso. Para exponerlo me sirvo de la edición larga, correspondiente al texto árabe editado por A. Badawi. Tras varias introducciones (del compilador anónimo, del supuesto traductor, Yahyā ibn alBițrīq, y de Aristóteles), comienzan los diez libros, en los que el autor o autores exponen las clases de Reyes, recomendaciones de política y de preceptiva moral, astrología, una amplia sección sobre la salud, sobre fisiognomía, sobre la justicia, sobre los escribas, sobre los embajadores, sobre el ejército, sobre la guerra y sobre las ciencias ocultas (onomancia, talismanes, alquimia, lapidario y herbario). En los dos primeros libros se hallan doctrinas sobre la virtud emparentadas con la Ética nicomaquea de Aristóteles.

Pero es el libro cuarto de la versión larga y del texto árabe el que llama nuestra atención. Su título reza de la siguiente manera: Sobre los ministros (wuzarā'), el número de ellos, cómo deben gobernar, la experiencia de sus consejos y el aspecto [o cualidad] (șūra) del intelecto que hay en ellos. Parecería que se va a ocupar de los ministros o visires de los reyes. Pero no. Su contenido es bastante heterogéneo y es en su comienzo donde encontramos la materia filosófica: Es una breve exposición de ideas neoplatónicas: la concepción del universo y la doctrina sobre la analogía entre el macrocosmos y el microcosmos. Es curioso señalar que esta parte del Sirr al-asrār fue ignorada por algunos traductores o comentadores de la obra así como por los metafísicos medievales que pudieron haber leído la obra, ${ }^{26}$ quizá porque consideraron que esta doctrina no era aristotélica. Se afirma por una parte la realidad de Dios y su creación como emanación jerárquica y, por otra, la realidad del hombre como elemento unificador de todas las esencias creadas. El concepto de 'emanación' (fayḍ) describe la relación que se da entre los diversos miembros de la jerarquía y significa literalmente 'derramarse', 'inundarse'.

He aquí el texto con el que comienza el capítulo:

¡Oh Alejandro! Comprende este tratado y sabe que su valor es grande. Para ti ciertamente he puesto en él una gran parte de la ciencia de la filosofía y la esencia (māhiyya) y constitución del intelecto. He revelado en él secretos divinos (asrār ilāhiyya) que necesariamente hay que exponer para tu información sobre la realidad del intelecto, cómo lo puso Dios en sus siervos y cómo alcanzan el conocimiento de todo esto. Esto es algo muy necesario para ti. Sé afortunado con ello, si Dios quiere.

25 Jacqueline Hamesse: Les auctoritates Aristotelis. Un florilège médiéval. Étude historique et édition critique, París: Béatrice-Nauwelaerts, 1974, p. 22, n. 19; textos en pp. 271-273.

26 Cf. Steve J. Williams: The Secret of Secrets. The Scholarly Career of a Pseudo-Aristotelian Text in the Latin Middle Ages, Ann Arbor: The University of Michigan Press, 2003, pp. 320-321. 
¡Oh Alejandro! Sabe que la primera cosa que el Creador, loada sea su grandeza, produjo fue una sustancia simple espiritual en el límite de la perfección, de la plenitud y de la excelencia, en la que se hallan las formas de todas las cosas. Se llama el Intelecto (al-'aql). Sabe que de esta sustancia procedió otra, inferior en rango, que se llama el Alma Universal (al-nafs al-kulliyya). Y que de esta Alma procedió otra sustancia que se llama la Materia (al-hayūlà). Por ser susceptible de recibir magnitudes, longitud, anchura y profundidad, llega a ser Cuerpo Absoluto. Después, el cuerpo recibe la forma (al-šakl) esférica, que es la más excelente de las formas, la de mejor posición y la más perdurable. De esta [forma esférica] son las esferas celestes y los astros, siendo la más pura y sutil de ella la primera. La esfera primera es la circundante y ellas llegan al límite extremo de la esfera de la luna; son nueve esferas, cada una de ellas en el interior de la otra. La primera y más superior de ellas es la esfera circundante. Luego está la esfera de las estrellas fijas; luego, la esfera de Saturno; luego, la esfera de Júpiter; luego, la esfera de Marte; luego, la esfera del Sol; luego, la esfera de Venus; luego, la esfera de Mercurio; luego, la esfera de la Luna; luego, la esfera de los elementos (arkān), ${ }^{27}$ que son: fuego, aire, agua y tierra. La tierra está en el centro de todas ellas. Es la más densa de los cuerpos en cuanto a sustancia y la más espesa en cuanto al cuerpo.

Cuando estas esferas fueron ordenadas unas dentro de otras, tal como lo había decidido la sabiduría del Creador, loada sea su grandeza, con una disposición admirable y con una hermosa distribución, las esferas giraron con sus cuerpos y sus estrellas alrededor de los cuatro elementos antes mencionados. Entonces comenzaron a sucederse la noche y el día, el verano y el invierno, el calor y el frío. Unos [elementos] se mezclaron con otros y entonces se combinó lo sutil con lo denso, lo pesado con lo ligero, lo caliente con lo frío, lo húmedo con lo seco. A lo largo del tiempo surgieron diversas clases de composiciones: los minerales, los vegetales y los animales.

Los minerales son todas aquellas cosas que se han condensado en el interior de la tierra, en lo profundo de los mares y en las concavidades de las montañas a partir de los vapores acumulados, de los humos ascendentes y de los vahos que se han contraído en las cuevas y en la atmósfera. Las tierras están compuestas en su mayor parte de ellos, como el oro, la plata, el hierro, el cobre, el estaño, ${ }^{28}$ las gemas, el corindón, ${ }^{29}$ el coral, el cinc, el vidrio y otros distintos de estos, que son conocidos y existen. ${ }^{30}$

Animal es todo cuerpo que se mueve, que siente y que se traslada de un lugar a otro con su propio cuerpo; lo aéreo es lo que predomina en él. Los vegetales son más nobles en composición que los minerales y los animales son más nobles en composición que los vegetales.

27 Término usado en la religión para designar los arkān al-dinn, los pilares de la religión, frente a ustuqus, el más usual como transliteración del griego estoijeion.

28 Leyendo qașdir y no qazdir.

29 En plural en el texto árabe, al-yawāqūt, de yāqūt, que también significa el jacinto.

30 Sobre la cuestión de los minerales, cf. J. A. García-Junceda: 'Los Meteorologica de Aristóteles y el De Mineralibus de Avicena', en Milenario de Avicena, Madrid: IHAC, 1981, pp. 37-63. 
El hombre es el más noble en composición de todos los animales; el elemento fuego ${ }^{31}$ es el que domina en él. En la composición del hombre se han unido todas las realidades ${ }^{32}$ de los seres simples y compuestos, porque el hombre está compuesto de un cuerpo denso y voluminoso y de un alma que es sustancia simple y espiritual.

Oh Alejandro, si estás decidido a conocer las realidades de los seres (haqā̄iq almawŷūa $\bar{t}$ ), te conviene comenzar por el conocimiento de tu alma, puesto que es la cosa más cercana a ti mismo; después, conoce las restantes cosas.

Sabe que el Alma Universal es una potencia espiritual que ha emanado (fādat) del Creador, loada sea su grandeza. Sabe que ella tiene dos potencias ${ }^{33}$ que se difunden en todos los cuerpos, tal como la luz del sol en las partes del aire: la primera de sus dos potencias es la referente al conocimiento y la segunda es la referente a la acción. Dios Altísimo la ha fortalecido con siete facultades: la apetitiva, la retentiva, la digestiva, la expulsiva, la nutritiva, la formativa y la de crecimiento. La acción de estas facultades en la composición del cuerpo del hombre consiste en hacer que el esperma llegue al útero y en disponerlo en él durante nueve ${ }^{34}$ meses. Cuando se ha completado este plazo que Dios Altísimo ha dispuesto, entonces se transmite la facultad del alma corpórea animal (quwwa alnafs al-hayawāniyya al-ŷusmāniyya), si Dios Altísimo quiere, desde ese lugar al espacio de esta casa ${ }^{35}$ y obtiene así otra disposición que se completa a los cuatro años. Después adquiere la facultad racional ${ }^{36}$ por la que interpreta los nombres de las cosas sensibles y obtiene así otra disposición que se completa a los quince años. Luego adquiere la facultad intelectiva (al-quwwa al-'āqila) por la que discierne los significados de las cosas sensibles (ma'āni al-maḥsūsāt) y obtiene así otra disposición que se completa a los treinta años. Luego adquiere la facultad sapiencial (al-quwwa al-hikamiyya) por la que percibe los significados de las cosas inteligibles y obtiene así otra disposición que se completa a los cuarenta años. Después adquiere la facultad angelical (al-quwwa al-malakiyya) que le ayuda y con ella obtiene otra disposición que se completa a los cincuenta años. Adquiere después la facultad propia de la ley (al-quwwa al-nāmūsiyya $)^{37}$ que le prepara para el lugar del retorno (al-ma‘ād) y con ella obtiene otra disposición para la otra vida. Si el alma se ha completado y se ha perfeccionado antes de separarse del cuerpo, entonces desciende (hasta ella) la facultad del Alma Universal, asciende con ella

31 Literalmente, la igneidad (al-nāriyya).

32 Las ideas, conceptos o significados (al-ma'ānì).

33 La versión latina señala tres: 'et habet tres vires', ed. Steele, p. 130,17.

34 En la versión latina: ‘septem', p. 130,24.

35 Es decir desde el útero al cuerpo del hombre.

36 Al-quwwa al-nātiqiqa. Podría ser también la facultad del lenguaje, aunque tanto la versión latina, p. 131,4, como la inglesa, p. 73,19, la traducen por 'racional'.

37 Obsérvese que utiliza el término nāmūs, trasliteración del griego nomos, y no el término islámico šarīa. 
hasta los ángeles ${ }^{38}$ y obtiene con ello otra disposición hasta que se une con la esfera del Intelecto, que le complace mucho'. ${ }^{39}$

Se ha dicho ${ }^{40}$ que esta emanación jerárquica del universo es propia del peripatetismo árabe, en especial de la lectura aviceniana de Aristóteles. Sin embargo, la jerarquía de Creador, Intelecto, Alma y Materia no se encuentra ni en al-Fārābī ni en Avicena, quienes establecen la siguiente jerarquía: Uno, que es el Ser primero, Ser necesario e Intelecto Primero; en segundo lugar, los diez Intelectos o Motores celestes con sus esferas, compuestas de intelecto y alma; finalmente, el mundo de la generación y corrupción. Este sistema de los diez Intelectos sólo se encuentra por vez primera en al-Fārābī. ${ }^{41}$

En cambio, la emanación jerárquica del Sirr al-asrār es la que se encuentra en los textos de los llamados Ijwān al-Ṣafā' o Hermanos de la Pureza, conjunto de autores del siglo X, que compusieron cincuenta y dos Epístolas (Rasāil ${ }^{42}$ que constituyen una enciclopedia del saber, catalogado en tres grandes grupos: ciencias prácticas, ciencias religiosas y ciencias filosóficas, que incluyen desde las matemáticas a la filosofía, pasando por la música, la mineralogía, la botánica y la alquimia, con elementos herméticos que debieron influir también en el texto del Sirr al-asrār. Repárese en el siguiente texto de los Ijwān, que se asemeja enormemente a lo expuesto al comienzo de la cita anterior del Sirr. Dicen los Ijwān:

'La primera cosa que el Creador produjo y llamó a la existencia es una sustancia simple, espiritual extremadamente perfecta en la que la forma de todas las cosas está contenida. Esta sustancia es llamada el Intelecto. De esta sustancia procede luego una segunda que en jerarquía está por debajo del primero y es llamada el alma Universal. Del Alma Universal procede otra sustancia que está bajo el Alma y que es llamada Materia Original. ${ }^{43}$ Ésta última es transformada en el Cuerpo

38 Literalmente 'la asamblea superior' (al-malā' al-a'à).

39 Ed. A. Badawi op. cit., pp. 130-132.

40 Cf. Steve J. Williams: The Secret of Secrets., op. cit., p. 320.

${ }^{41}$ Cf. Al-Fārābī, Kitâb mabâdi' ârâ ahl al-madîna al-fâdila, ed. R. Walzer, Oxford: Clarendon Press, 1985; trad. española: Al-Fârâbî: La ciudad ideal, trad. M. Alonso, Madrid: Ed. Tecnos, 1985. AlFârâbî's The Political Regime (Al-siyâsa al-madaniyya also known as the Treatise on the Principles of Beings), Arabic text, edited with an introduction and notes by F. M. Najjar, Beirut: Imprimerie Catholique, 1964; trad. española, Al-Farabi: Obras filosóficas y políticas, traducción con texto árabe, introducción y notas de R. Ramón Guerrero, Madrid: Trotta, 2008.

42 Ijwān al-Ṣafā’': Rasā’il, Beirut: Dâr Sâdir, 4 vols., 1957.

43 La jerarquía esbozada hasta aquí sigue en gran parte la de Ŷābir, salvo que éste en su Kitāb aljamsin sitúa la Naturaleza después del alma. Kraus: Jabir ibn Hayyan, II, 150. 
Absoluto, es decir, la Materia Segunda que tiene longitud, anchura y profundidad'. ${ }^{44}$

'Has de saber, hermano, que la primera cosa que el Creador, exaltado sea, originó y creó a partir de la luz de su unidad fue una substancia simple, que se llama Intelecto Agente, de la misma manera que produjo el dos a partir del uno por repetición. Luego produjo el Alma celeste universal a partir de la luz del Intelecto, de la misma manera que creó el tres por adición del uno al dos. Luego produjo la Materia Primera a partir del movimiento del Alma, de la misma manera que produjo el cuatro por adición del uno al tres', ${ }^{45}$

Hay que señalar también el carácter religioso que se le da al proceso emanativo, puesto que el Primer Principio no es el Uno, como en los neoplatónicos griegos, ni el Ser necesario, Ser Primero, Causa primera o Intelecto de los filósofos árabes como al-Fārābī y Avicena, sino 'el Creador', como también se encuentra a veces en los textos de los Ijwān al-Ṣafā'.

El sistema filosófico que se encuentra en esas Epístolas es una mezcla de doctrinas pitagóricas, platónicas y neoplatónicas, en lenguaje aristotélico, en el que el núcleo es la jerarquía descendente del Uno, según la doctrina de la emanación, realizada según combinaciones numéricas procedentes del pitagorismo, y la exposición del origen celeste del alma y de su retorno a la Unidad, tras la purificación de la materia.

La creación y el universo entero son presentados dentro de los esquemas de la revelación coránica, interpretados con los paradigmas neoplatónicos de tipo emanantista. Por eso, al Uno neoplatónico lo llaman el Creador, identificado con el Dios de la revelación. Conociéndose a sí mismo, creó, por el hecho mismo de conocerse, o hizo emanar de una sola vez y de repente, fuera del tiempo y del espacio, al Intelecto, el cual, a su vez, conociéndose a sí mismo y a Dios, engendró el Alma Universal del mundo. Es entonces cuando el mundo del espíritu quedó constituido. El mundo material, por su parte, es producto sucesivo del Alma Universal ya mencionada, la cual, en su parte inferior, va engendrando a través de 'largas eras infinitas' de tiempo al mundo material o 'Materia Primera'.

Éste surge según el siguiente orden: primero, se engendra la Naturaleza que es una 'potencia del Alma Universal', o, en otros términos, 'un acto' de esa misma alma. Por la acción del Alma Universal surgen en la naturaleza los cuatro elementos (tierra, agua, aire y fuego), apareciendo así la Materia Segunda o

${ }^{44}$ La cita aparece en S. H. Nasr: An Introduction to Islamic Cosmological Doctrines, Cambridge (MA): The Belknap Press of Harvard University Press, 1965, p. 52, donde remite a F. Dieterici: Die Lehre von der Weltseele, p. 15; y señala Rasā’il, II, 4-5, de la edición de El Cairo. No corresponde en nada a la edición de Beirut.

45 Rasâ’il, vol. I, p. 54.7-11. 
Cuerpo del Mundo. Aquí se interrumpe todo el proceso emanativo neoplatónico que explica filosóficamente la creación. Los cuatro elementos se combinan y forman, primero, los minerales, luego, los vegetales, a continuación, los animales $y$, finalmente, como culminación y resumen de todo el proceso, el hombre. El ser humano es, de este modo, un compuesto de elementos minerales, vegetales, animales y de alma espiritual. En consecuencia, resulta ser una síntesis perfecta de toda la creación, un cosmos en pequeño. Enseñan así la idea del hombre como microcosmos, como reflejo del universo creado por Dios, que conociéndose a sí mismo llega al conocimiento de su creador: 'Quien mejor se conoce, conoce mejor a su Creador'. ${ }^{46}$

La idea del microcosmos se encuentra en el texto del Sirr al-asrār expuesta de la siguiente manera:

'Cuando Dios creó al hombre y lo estableció como el más noble de los animales, le dio mandatos y prohibiciones, castigos y premios. Constituyó su cuerpo como una ciudad, de la que el intelecto era el rey. Estableció para él cinco ministros (wuzarā') para que lo ayudaran a gobernarla y le presentaran todo lo que necesitara y le fuera útil, y lo guardaran de todo lo que le fuera nocivo. Él no puede subsistir ni perfeccionarse sin ellos. Estableció para cada uno de ellos un aspecto exclusivo distinto del de su compañero y una cualidad propia que no fuera compartida por ningún otro. Por la unión de las opiniones de ellos en él, se estableció la perfección de sus asuntos y la constitución de sus obras. Los cinco ministros son los cinco sentidos: ojos, oídos, lengua (lisān), nariz y manos (al-yad)'. ${ }^{47}$

'Sabe, oh Alejandro, que Dios Altísimo y Glorioso no ha creado un ser más noble que el hombre, ${ }^{48}$ ni ha reunido en ningún animal lo que ha reunido en el hombre. Tampoco hay en ninguno de los animales una cualidad innata que no se encuentre también en el hombre. Pues es valiente como el león, tímido como la liebre, generoso como el gallo, cauto como el cuervo... En resumen, Alejandro, no hay animal ni vegetal ni mineral ni esfera ni astro ni ninguno de los seres del universo que tenga alguna propiedad que no se encuentre en el hombre. Por eso se le llama microcosmos ('ālam sagir)'. ${ }^{49}$

El hombre es designado por el término 'hijo de Adán' (Ibn Ādam) y los Ijwān se ocupan del Adán celeste y del Adán terrestre.$^{50}$ Es descrito como un compuesto de dos sustancias, una física, el Cuerpo, y la otra espiritual, el Alma. Está en condiciones de simbolizar el Universo entero, compuesto también, como se ha

46 Rasā'il, vol. III, pp. 178-179.

47 Ed. A. Badawi citada, p. 132.

48 Literalmente: el hijo de Adán.

49 Ed. A. Badawi, pp. 139-140.

50 Cf. Yves Marquet: La philosophie des Iñwān al-Ṣafä’, Alger: Études et Documents, 1975, pp. 208-218. 
visto, de Cuerpo (las cosas sensibles) y Alma (el Alma Universal). El texto del Sirr utiliza la comparación del cuerpo del hombre con una ciudad y de su alma con el rey de ella tal como hacen los Ijwān, y se sirve de los mismos ejemplos al establecer las correspondencias entre el hombre y los animales. Así dice el texto de los Ijwān, después de reconocer la asimilación de cuerpo y alma con una ciudad y su rey:

'Sabe, oh hermano, que todas las especies de animales tienen una propiedad que les es innata y que todas ellas se encuentran en el hombre, pues él es valiente como el león, tímido como la liebre, generoso como el gallo, avaro como el perro... En resumen, no hay animal ni vegetal ni mineral ni esfera ni astro ni ninguno de los seres del universo que tenga alguna propiedad que no se encuentre en el hombre.... Por causa de esto, los sabios han dicho que el hombre es uno después de toda multiplicidad, de la misma manera que el Creador es uno antes de toda multiplicidad... y lo llaman microcosmos ('ālam sagir)'. ${ }^{51}$

En conclusión, aunque el texto del Sirr al-asrār no haga más explícito lo que afirma, es posible sin embargo deducir que en él, siguiendo el modelo establecido por los Ijwān al-Ṣafā', pretende explicar el proceso creativo de Dios.

De la Unidad absoluta (Dios como Uno que no tiene par ni compañero con que pueda equipararse) sólo procede el Intelecto, que constituye el primer ser emanado, con el que se inicia la multiplicidad. Este Intelecto, supremo y perfecto, al conocer la Unidad de Dios de la que procede, conoce también la dualidad de sí misma respecto de Dios, y, por tanto, está abierto y capacitado para conocer cualquier multiplicidad, como la de las formas arquetípicas que de manera unitaria e indivisa Dios ha puesto en él, arquetipos que tienen que ver con las ideas-paradigma de Platón. El Intelecto, al engendrar al Alma, genera simultáneamente en dicha alma los arquetipos que ya no están fundidos en una unidad, como en el Intelecto, sino que se despliegan en una multitud de modelos y paradigmas, a través de los cuales (y a través del mismo Intelecto y Alma) Dios hace todas las cosas del mundo.

Este proceso es reversible: desde la multiplicidad de las cosas se puede llegar a la unidad (tawhìd) por el camino de la eliminación de dicha multiplicidad y, por tanto, de la materialidad. Es la vuelta del mundo y del hombre al Dios-Uno, eliminando por completo no sólo la multiplicidad corporal, sino también la espiritual del Alma y del Intelecto. Todo este proceso, el descendente y el ascendente, ha de tener sus pasos, sin que sea posible saltar ninguno de ellos: así, el hombre llegará a la unidad de Dios solamente a través de la Naturaleza, del Alma y del Intelecto. Es el camino de vuelta a la unidad, tanto en el orden cósmico como en el humano.

51 Ijwān al-Ṣafā': Rasā’il, vol. III, pp. 474-475. 
Volviendo a la estructura del mundo en su totalidad y dejando aparte la formación de los seres particulares (elementos, minerales, vegetales, animales y hombre), el cosmos está constituido a la manera de la ciencia neoplatónica y griega, en general por una serie de gigantescas esferas celestes concéntricas que el texto del Sirr al-asrār, siguiendo el neoplatonismo de al-Fārābī y de Avicena en este caso, cifra en nueve, que son las de la Luna, Mercurio, Venus, Sol, Marte, Júpiter, Saturno, Esfera de las Estrellas Fijas, y la Esfera circundante. Del esquema de los Ijwān al-Ṣafā' eliminan la Esfera de los signos del Zodíaco. La vida del hombre y los acontecimientos de su existencia discurren por debajo de la esfera de la Luna, influyendo todos los demás astros superiores y a través de ella en su manera de ser y en su destino.

Este conjunto de esferas del universo, ensambladas unas dentro de otras y en perfecto contacto mutuo, ${ }^{52}$ constituyen una total unidad jerárquica, sometida a la unidad del mundo espiritual del Intelecto y del Alma, los cuales están sometidos a la unidad del Dios único.

Este esquema neoplatónico, tan vivo, profundo y coherente, venía a subrayar la presencia de los otros neoplatonismos ya existentes, tanto el de los filósofos propiamente dichos, como el expuesto por algunos místicos o sufíes, en quienes también es posible hallar elementos tomados de la doctrina neoplatónica y utilizados para la exposición de sus experiencias místicas.

52 Esta idea de un universo compuesto de esferas concéntricas que se tocan unas a otras, sin dejar vacío alguno entre ellas, es propio de la cosmología platónica y aristotélica, para quienes la nada no existe, debiendo estar todos los seres del universo en contacto mutuo. 